\title{
Tuberous Breast
}

\section{Mama Tuberosa}

Joana SIMÕES DA SILVA $\square^{1}$, Paula ALVES TEIXEIRA ${ }^{1}$, Maria Teresa ROSMANINHO ${ }^{1}$

Acta Med Port 2020 Nov;33(11):767-767 - https://doi.org/10.20344/amp.12348

Keywords: Breast/surgery; Breast Diseases

Palavras-chave: Doenças da Mama; Mama/cirurgia

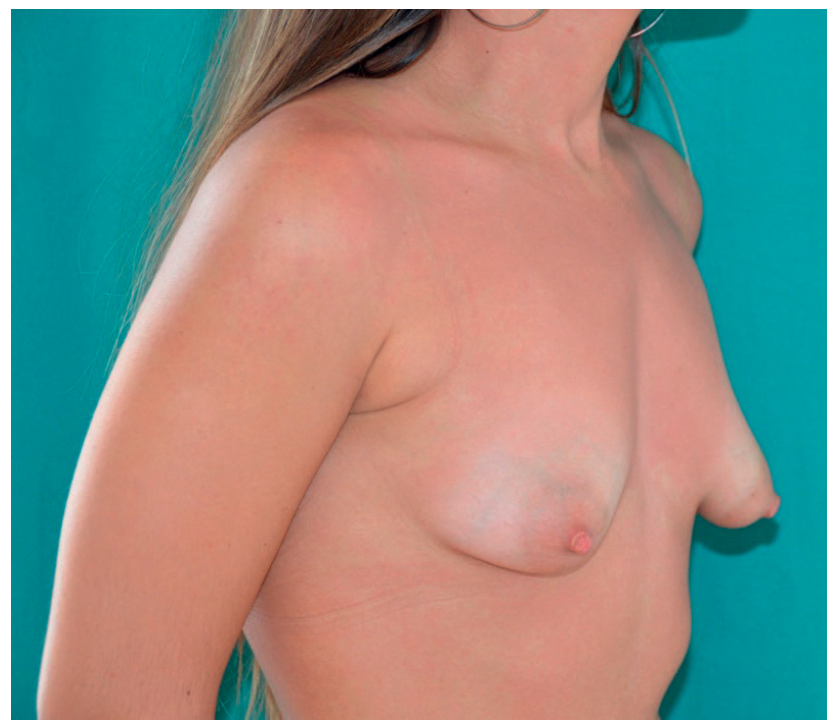

Figure 1 - Preoperative tuberous breast - lateral view

A 22-year-old female patient, with no relevant medical history complained about the shape of her breasts, which had been the source of her low self-esteem since early adolescence. The physical examination revealed asymmetrical, tubular hypoplastic breasts and enlarged areolas (Fig. 1). The patient was referred to the Plastic Surgery department of the referral hospital, where a diagnosis of type III tuberous breast was made and reconstructive surgery with (breast) implants was proposed (Fig. 2).

Tuberous breast is a rare deformity ${ }^{1}$ with onset at the

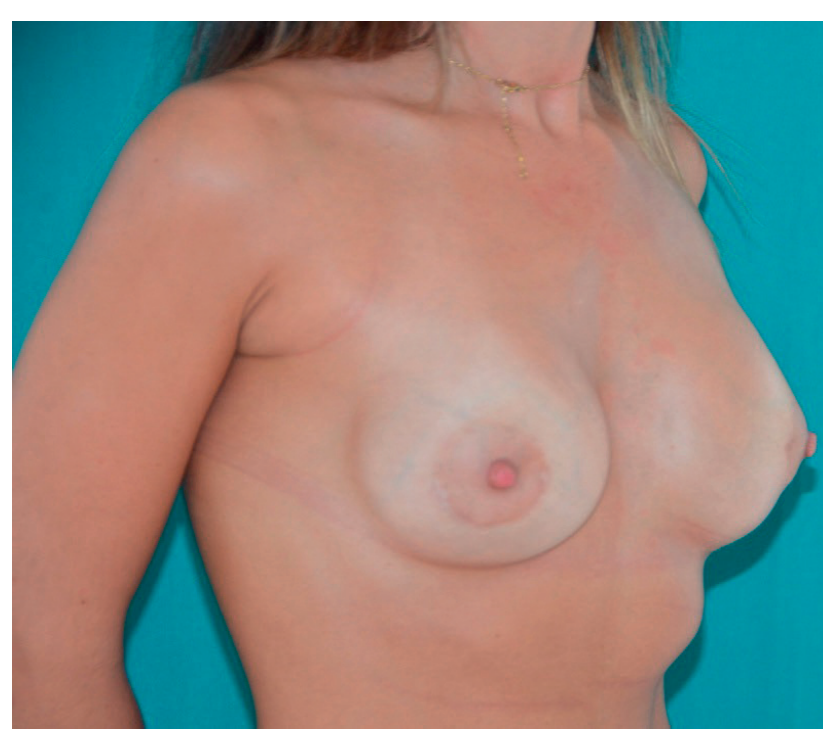

Figure 2 - Periareolar surgical correction and subfascial breast augmentation with anatomical textured implants (size $255 \mathrm{cc}$ ) - lateral view

beginning of pubertal growth. ${ }^{1-3}$ The main signs are hypoplasia and tubular shape of the breast, which may be uni or bilateral, symmetric or asymmetric., ${ }^{2,3}$ The diagnosis is clinical and the treatment is surgical. This condition conveys a significant psychological burden, causing low self-confidence, anxiety, depression, peer rejection and psychosexual dysfunction..$^{1,3}$ Early diagnosis and surgical correction are key in the treatment and prevention of psychological symptoms. $^{3}$

PROTECTION OF HUMANS AND ANIMALS: The authors declare that the procedures were followed according to the regulations established by the Clinical Research and Ethics Committee and to the 2013 Helsinki Declaration of the World Medical Association.

DATA CONFIDENTIALITY: The authors declare having followed the protocols in use at their working center regarding patients' data publication.

INFORMED CONSENT: Obtained.

CONFLICTS OF INTEREST: All authors report no conflict of interest.

FUNDING SOURCES: This study received no specific grant from any funding agency in the public, commercial, or not-for-profit sectors.

\section{REFERENCES}

1. Dessy LA, Mazzocchi M, Corrias F, Sorvillo V, Scuderi N. Correction of tuberous breast with small volume asymmetry by using a new adjustable implant. Eur Rev Med Pharmacol Sci. 2013;17:977-83.

2. Silva-Vergara C, Fontdevila J, Weshahy O. Fat grafting technique, a paradigm shift in the treatment of tuberous breast. World J Plast Surg. 2018;7:72-7.

3. Winocour S, Lemaine V. Hypoplastic breast anomalies in the female adolescent breast. Semin Plast Surg. 2013;27:42-8.

1. Unidade de Saúde Familiar Águeda Mais Saúde. Agrupamento Centro de Saúde do Baixo Vouga. Águeda. Portugal.

$\bowtie$ Autor correspondente: Joana Simões da Silva. joanasimoess87@gmail.com

Recebido: 20 de maio de 2019 - Aceite: 10 de julho de 2019 | Copyright @ Ordem dos Médicos 2020 